Audiology

Neurotology
Audiol Neurotol 2016;21:88-97

DOI: $10.1159 / 000443822$
Received: December 9, 2015 Accepted: January 4, 2016

Published online: March 30, 2016

\title{
Histopathology of the Human Inner Ear in the p.L114P COCH Mutation (DFNA9)
}

\author{
Barbara J. Burgess ${ }^{a}$ Jennifer T. O'Malley ${ }^{a}$ Takefumi Kamakura ${ }^{a, d}$ \\ Kris Kristiansen $^{a}$ Nahid G. Robertson ${ }^{b, c}$ Cynthia C. Morton ${ }^{b-f}$ \\ Joseph B. Nadol Jr. a, d \\ ${ }^{a}$ Human Otopathology Laboratory, Department of Otolaryngology, Massachusetts Eye and Ear Infirmary, \\ Departments of ${ }^{b}$ Obstetrics, Gynecology, and Reproductive Biology and 'Pathology, Brigham and Women's \\ Hospital, and ${ }^{\mathrm{d} H a r v a r d}$ Medical School, Boston, Mass., and ${ }^{\mathrm{e}}$ Broad Institute of MIT and Harvard, \\ Cambridge, Mass., USA; ${ }^{f}$ School of Psychological Sciences, University of Manchester, Manchester, UK
}

\section{Key Words}

Histopathology · Human inner ear · p.L114P COCH

mutation · DFNA9 - Immunostaining $\cdot$ Cochlear implant

\begin{abstract}
The histopathology of the inner ear in a patient with hearing loss caused by the p.L114P COCH mutation and its correlation with the clinical phenotype are presented. To date, 23 $\mathrm{COCH}$ mutations causative of DFNA9 autosomal dominant sensorineural hearing loss and vestibular disorder have been reported, and the histopathology of the human inner ear has been described in 4 of these. The p.L114P COCH mutation was first described in a Korean family. We have identified the same mutation in a family of non-Asian ancestry in the USA, and the temporal bone histopathology and clinical findings are presented herein. The histopathology found in the inner ear was similar to that shown in the 4 other $\mathrm{COCH}$ mutations and included degeneration of the spiral ligament with deposition of an eosinophilic acellular material, which was also found in the distal osseous spiral lamina, at the base of the spiral limbus, and in mesenchymal tissue at the base of the vestibular neuroepithelium. This is the first description of human otopathology of the COCH p.L114P mutation. In addition, it is the only case with otopathology characterization
\end{abstract}

in an individual with any $\mathrm{COCH}$ mutation and residual hearing, thus allowing assessment of primary histopathological events in DFNA9, before progression to more profound hearing loss. A quantitative cytologic analysis of atrophy in this specimen and immunostaining using anti-neurofilament and anti-myelin protein zero antibodies confirmed that the principal histopathologic correlate of hearing loss was degeneration of the dendritic fibers of spiral ganglion cells in the osseous spiral lamina. The implications for cochlear implantation in this disorder are discussed.

(c) 2016 S. Karger AG, Basel

\section{Introduction}

Mutations in $\mathrm{COCH}$, encoding the secreted protein cochlin, cause autosomal dominant nonsyndromic sensorineural hearing loss (DFNA9). To date, $23 \mathrm{COCH}$ mutations (21 missense and 2 in-frame deletions) have been reported [Bae et al., 2014; Tsukada et al., 2015]. The common clinical phenotype includes adult-onset progressive, bilaterally symmetric sensorineural hearing loss with reduced word recognition scores. The histopathology of the human inner ear has been described in 4 of these mutations (table 1). In all 4 cases, the sensorineural loss was

\section{KARGER}

E-Mail karger@karger.com

www.karger.com/aud
(C) 2016 S. Karger AG, Basel

$1420-3030 / 16 / 0212-0088 \$ 39.50 / 0$
J.B. Nadol Jr., MD

Massachusetts Eye and Ear Infirmary

243 Charles Street

Boston, MA 02114 (USA)

E-Mail joseph_nadol@meei.harvard.edu 
Table 1. Published human cochlear histopathology of DFNA9

\begin{tabular}{llll}
\hline No. & Kindred & Mutation & Reference \\
\hline 1 & 1W & V66G & $\begin{array}{l}\text { Khetarpal et al., 1991 } \\
\text { Khetarpal, 1993, 2000 } \\
\text { Robertson et al., 1998 } \\
\end{array}$ \\
& & Merchant and Nadol, 2010 \\
\hline 2 & 1Su & G88E & $\begin{array}{l}\text { Khetarpal et al., 1991 } \\
\text { Robertson et al., 1998 } \\
\end{array}$ \\
& & Merchant and Nadol, 2010 \\
\hline 3 & 1St & W117R & $\begin{array}{l}\text { Robertson et al., 1998 } \\
\text { Merchant et al., 2000 }\end{array}$ \\
\hline 4 & & P51S & Robertson et al., 2006 \\
\hline
\end{tabular}

severe to profound at the time of death, and in all 4 cases there was a clinical history of vestibular dysfunction [Bae et al., 2014]. The histopathology that has been described includes degeneration of the spiral ligament with loss of cellularity and deposition of an eosinophilic acellular material, which was also found in the distal osseous spiral lamina and limbus. The amorphous material has been shown by immunohistochemistry to be consistent with mutated cochlin [Robertson et al., 2001, 2006]. The organ of Corti demonstrated loss of some outer and inner hair cells. However, the principal histopathologic correlate of the sensorineural loss appeared to be degeneration of the dendritic processes of the spiral ganglion cells, greater in degree than the loss of spiral ganglion cell bodies [Merchant and Nadol, 2010]. In addition to the cochlear findings, there was severe degeneration of the stroma of both the cristae and the maculae, with loss of cellularity and deposition of eosinophilic acellular material similar to that described in the cochlea. Severe degeneration of peripheral processes of Scarpa's ganglion has also been described [Merchant et al., 2000; Robertson et al., 2006].

The p.L114P COCH mutation was first identified by Choi et al. [2013] in a Korean family. However, no otopathology or detailed clinical history was presented. We have identified the same mutation in a family in the USA, and herein we present and discuss temporal-bone findings of L114P mutations, representing the fifth $\mathrm{COCH}$ mutation for which human otopathology is currently available. However, in this case, unlike in previous ones with a characterized histopathology, there was considerable retained hearing in a 42 -year-old man, providing an opportunity to study the degenerative process of the inner ear prior to progression to profound deafness.
The physiologic role of cochlin is not fully understood. $\mathrm{COCH}$ is expressed not only in cochlear and vestibular organs but also in the eye, spleen, thymus, brain, and cerebellum, all at much lower levels than in the inner ear [Bhattacharya, 2006]. Cochlin is a secreted protein with 3 functional domains: an N-terminal factor C homology, also known as the LCCL domain, and 2 von Willebrand factor A domains (vWFA1 and vWFA2). There is mounting evidence to suggest that the LCCL domain may be involved in host defense mechanisms. Py et al. [2013] reported expression of Coch by follicular dendritic cells in mouse spleen and lymph nodes and demonstrated involvement of cochlin in the systemic innate immune response, with mechanisms yet to be fully characterized. The von Willebrand domains are thought to associate with extracellular matrix proteins (typically fibrillar collagens), but a further possible function of these domains has not been characterized.

The mechanism by which mutated cochlin is involved in disease processes is likewise not fully understood. It has been suggested that mutated cochlin may aggregate [Robertson et al., 2001, 2003; Bhattacharya, 2006] and interfere with extracellular matrix protein interactions. In the cochlea, mutated cochlin may have a toxic effect on the dendritic processes of spiral ganglion cells and perhaps vestibular neurons [Merchant et al., 2000; Robertson et al., 2006] as a primary effect or secondary to disruption of ionic cycling particularly in the spiral ligament. It is thought that the pathologic effect of mutated cochlin is due to a gain of function rather than haploinsufficiency [Robertson et al., 2006]. Interestingly, cochlin aggregates may have a role in causing glaucoma through their deposition in the trabecular meshwork of the eye [Bhattacharya, 2006].

\section{Materials and Methods}

\section{Temporal Bone Acquisition}

Temporal bone specimens were obtained in compliance with Human Subject Assurance No. FWA00006221 (exemption 4) from the Massachusetts Eye and Ear Infirmary.

Temporal Bone Preparation and Light Microscopy

Temporal bones were removed for further study approximately $48 \mathrm{~h}$ after death, fixed in $10 \%$ formalin, decalcified with ethylene diamine tetra-acetic acid (EDTA), dehydrated in graded alcohols, and embedded in celloidin. Serial sections were cut at a thickness of $20 \mu \mathrm{m}$. Every tenth section was stained with hematoxylin and eosin (H\&E) and placed on glass slides. The right temporal bone was sectioned on a vertical plane because of the radiologic evidence during life of a dehiscence of the superior semicircular canal. The 


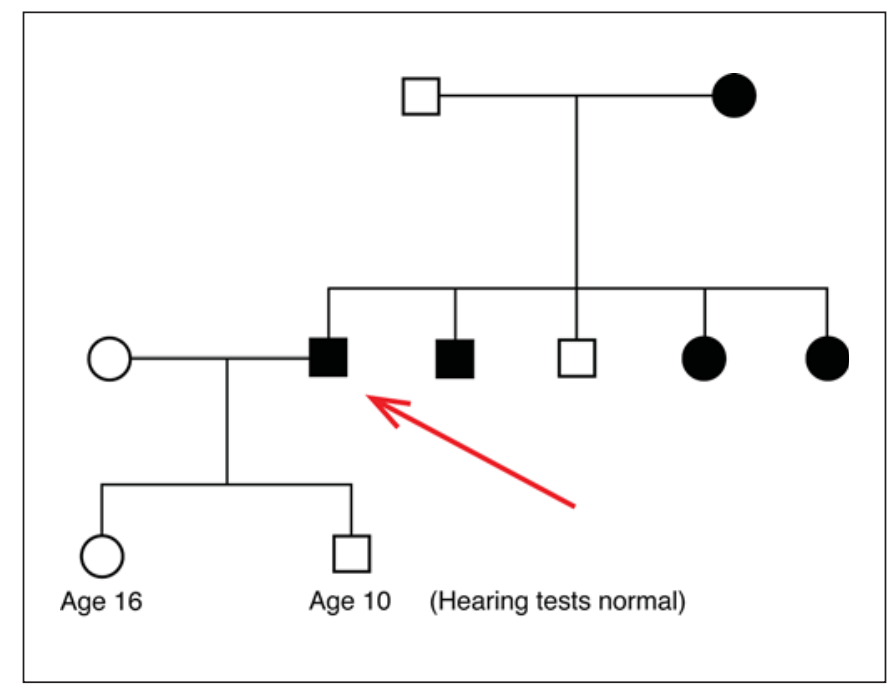

Fig. 1. Pedigree with the propositus marked by the arrow.

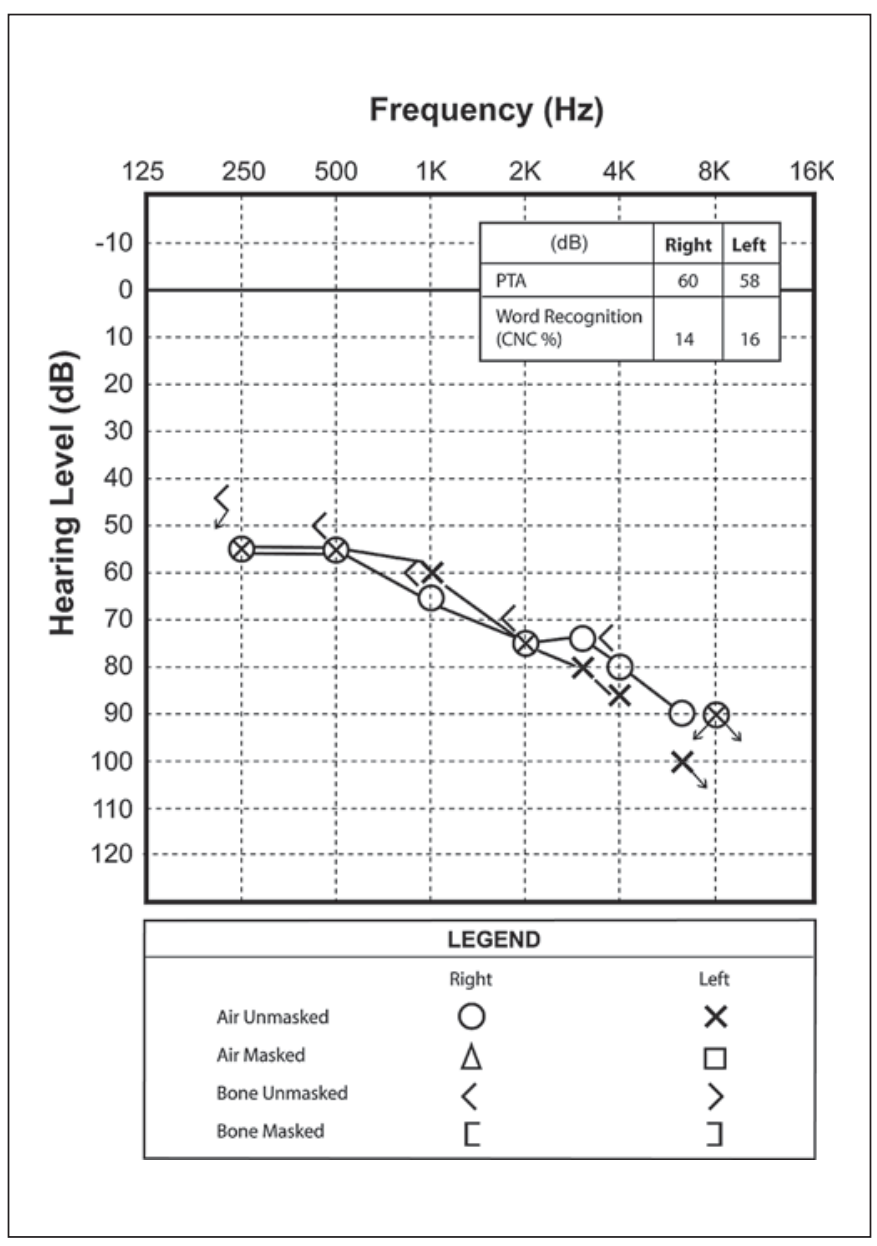

Fig. 2. Audiogram of the patient obtained 2 weeks prior to death. PTA $=$ Pure tone average; $\mathrm{CNC}=$ consonant-nucleus-consonant. left temporal bone was sectioned on the conventional axial (horizontal) plane and reconstructed in 2 dimensions for quantification of cellular elements.

\section{Neurofilament and Myelin Protein Immunostaining}

After removal of the celloidin embedding medium [O'Malley et al., 2009a], sections were incubated with primary antibodies for $14 \mathrm{~h}$ in a humid chamber and rinsed in 3 washes of PBS. Secondary antibodies diluted 1:200 were applied and incubated for $1 \mathrm{~h}$. Following 3 rinses in PBS, avidin biotin horseradish peroxidase (standard ABC Kit) (Vector Labs, Burlingame, Calif., USA) was applied to the sections and they were incubated for $1 \mathrm{~h}$, followed by 3 washes in PBS. Colorization was performed using $0.01 \%$ diaminobenzidine and $0.01 \% \mathrm{H}_{2} \mathrm{O}_{2}$ for $5-10 \mathrm{~min}$, followed by rinsing, dehydration, and cover-slipping as described by O'Malley et al. [2009b]. Selected sections were stained using anti-myelin protein zero antibody (Abcam), or anti-neurofilament antibody (Boehringer Mannheim).

\section{DNA Extraction and Sequencing}

Sanger sequencing was employed to evaluate $\mathrm{COCH}$ exons 4 and 5 (encoding the LCCL domain, which harbors the majority of known $\mathrm{COCH}$ mutations) in the following manner. Ten milligrams of muscle obtained at autopsy and preserved at $-80^{\circ} \mathrm{C}$ was used for DNA extraction using a Gentra Puregene Tissue Kit (Qiagen, Redwood City, Calif., USA), in accordance with the manufacturer's protocol, yielding approximately $5 \mu \mathrm{g}$ of genomic DNA. Approximately $25 \mathrm{ng}$ of this genomic DNA was used as a template for PCR amplification, employing Platinum PCR Supermix (Invitrogen, Waltham, Mass., USA) with $\mathrm{COCH}$ primers flanking exon 4 (forward: $5^{\prime}$-cttaaatctcacactgtagtc- $3^{\prime}$, reverse: $5^{\prime}$-aaaggaaataatcacgtctgc- $3^{\prime}$ ) and exon 5 (forward: $5^{\prime}$-tctttagatgacttccctgatgag- $3^{\prime}$, reverse: $5^{\prime}$-tcacaggtttttccatcaaggtta- $\left.3^{\prime}\right)$. After PCR amplification, primers were removed using a Qiagen Mini Elute PCR Purification Kit, followed by Sanger sequencing of PCR products at the Massachusetts General Hospital DNA Sequencing Core Facility. Trace sequences were read using Snap Gene Viewer software version 2.7.2 (GSL Biotech LLC, Chicago, Ill., USA).

\section{Results}

\section{Clinical History and Findings}

This 42-year-old male had a history of progressive, bilateral, down-sloping sensorineural hearing loss first noted at approximately age 30 years. Hearing loss was also present in his mother, 2 sisters, and 1 of 2 brothers, suggesting a genetic etiology (fig. 1). His mother was said to have done well with a cochlear implant as treatment for her sensorineural loss. Over the 10 years prior to his death, a progressive down-sloping sensorineural loss with a decrement in speech discrimination scores was noted. The last audiogram was performed 2 weeks prior to death and is shown in figure 2. A CT scan of the temporal bones was done at age 42 years. This demonstrated a questionable bony dehiscence of the right superior
90
Audiol Neurotol 2016;21:88-97 DOI: $10.1159 / 000443822$
Burgess/O’Malley/Kamakura/Kristiansen/ Robertson/Morton/Nadol Jr. 
Fig. 3. Sanger sequencing chromatograms showing a heterozygous c.T341C missense mutation (resulting in a p.L114P amino acid change) in $\mathrm{COCH}$ exon 5. Overlapping peaks of nucleotides $\mathrm{T}$ and $\mathrm{C}$ in the sense strand (top) and complementary nucleotides $A$ and $G$ in the antisense strand (bottom), indicated by arrows, show the presence of both normal and mutated alleles.
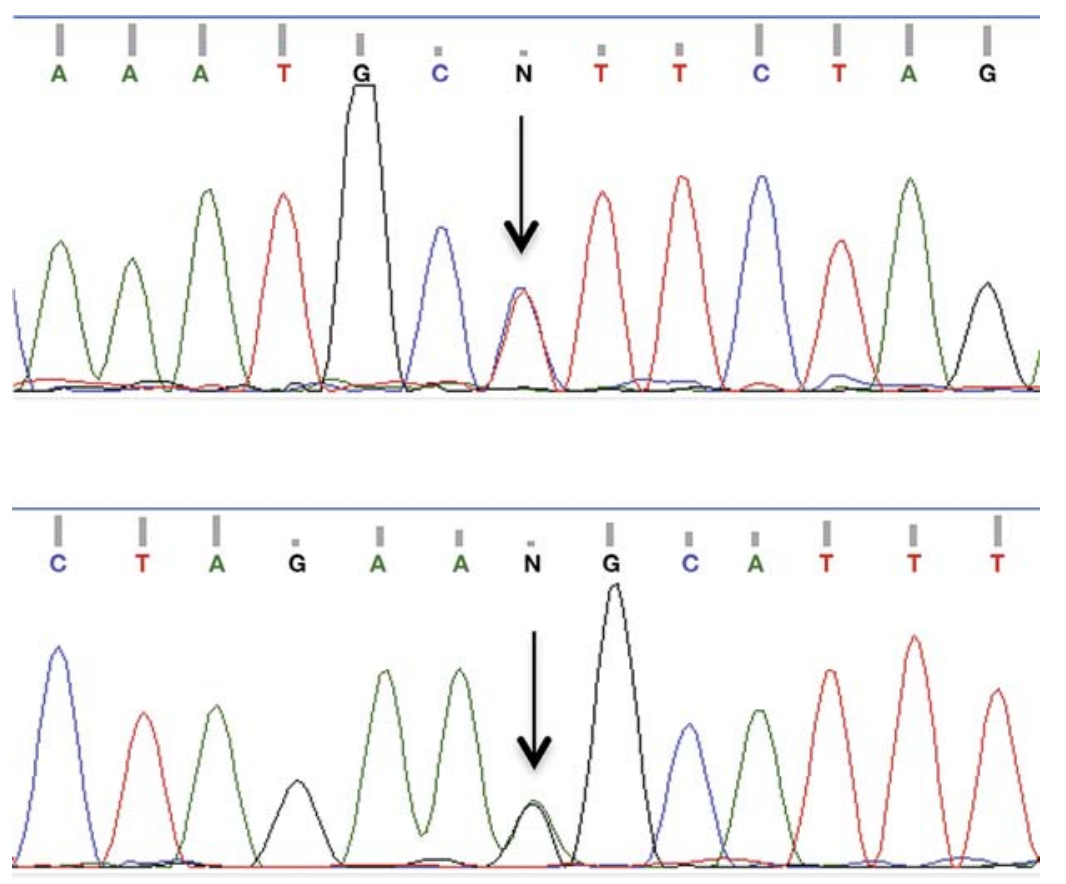

semicircular canal but no other abnormality. There was no history of vestibular complaints. The patient's past medical history included anaplastic T-cell non-Hodgkin's lymphoma diagnosed 6 years prior to death and treated with full-body radiation, an allogenic stem cell transplant, and chemotherapy. The treatment was complicated by graft-versus-host disease. Postmortem examination showed no evidence of residual lymphoma. There was evidence of gastrointestinal graft-versus-host disease and healing pneumonitis of both lungs.

\section{Histopathologic Findings}

Left Ear. Prominent throughout the cochlea was a diffuse loss of cellularity and a deposit of amorphous material in the spiral ligament, the distal end of the osseous spiral lamina, and the base of the limbus (fig. 4), consistent with DFNA9 as the underlying disorder [Merchant et al., 2000]. Although there was a significant postmortem artifact, there was preservation of the stria vascularis and some inner and outer hair cells in all 3 turns of the cochlea. A cytocochleogram is shown in figure 5 , which illustrates the preservation and degeneration of elements of the cochlea.

Cochlear Neurons. The total spiral ganglion cell count was 14,279 , which represented $53 \%$ of the normal age- matched controls. The dendritic processes between the spiral ganglion cells and the organ of Corti demonstrated more severe degeneration compared to the spiral ganglion cell bodies (fig. 5), best illustrated using immunostaining for myelin protein and neurofilaments (fig. $6,7)$.

Vestibular System. There was evidence of mild to moderate atrophy of the neuroepithelium of the 3 semicircular canals and the macula utriculi and macula sacculi. There was an amorphous deposit in the mesenchymal tissue between the cribrose area of the vestibular end organs and the neuroepithelium (fig. 8). The total Scarpa's ganglion cell count was 11,288 , which represented $56 \%$ of the normal age-match controls. Degeneration of distal vestibular dendritic fibers at the base of the neuroepithelium was demonstrated using antineurofilament immunostaining (fig. 9). There was deposition of a mixture of basophilic and eosinophilic amorphous material in the incudomalleal joint (fig. 10) and the incudostapedial joint, as well as near the umbo of the tympanic membrane. The stapediovestibular joint was normal.

Right Ear. There was a small dehiscence of the bony superior semicircular canal. Otherwise, the findings in 


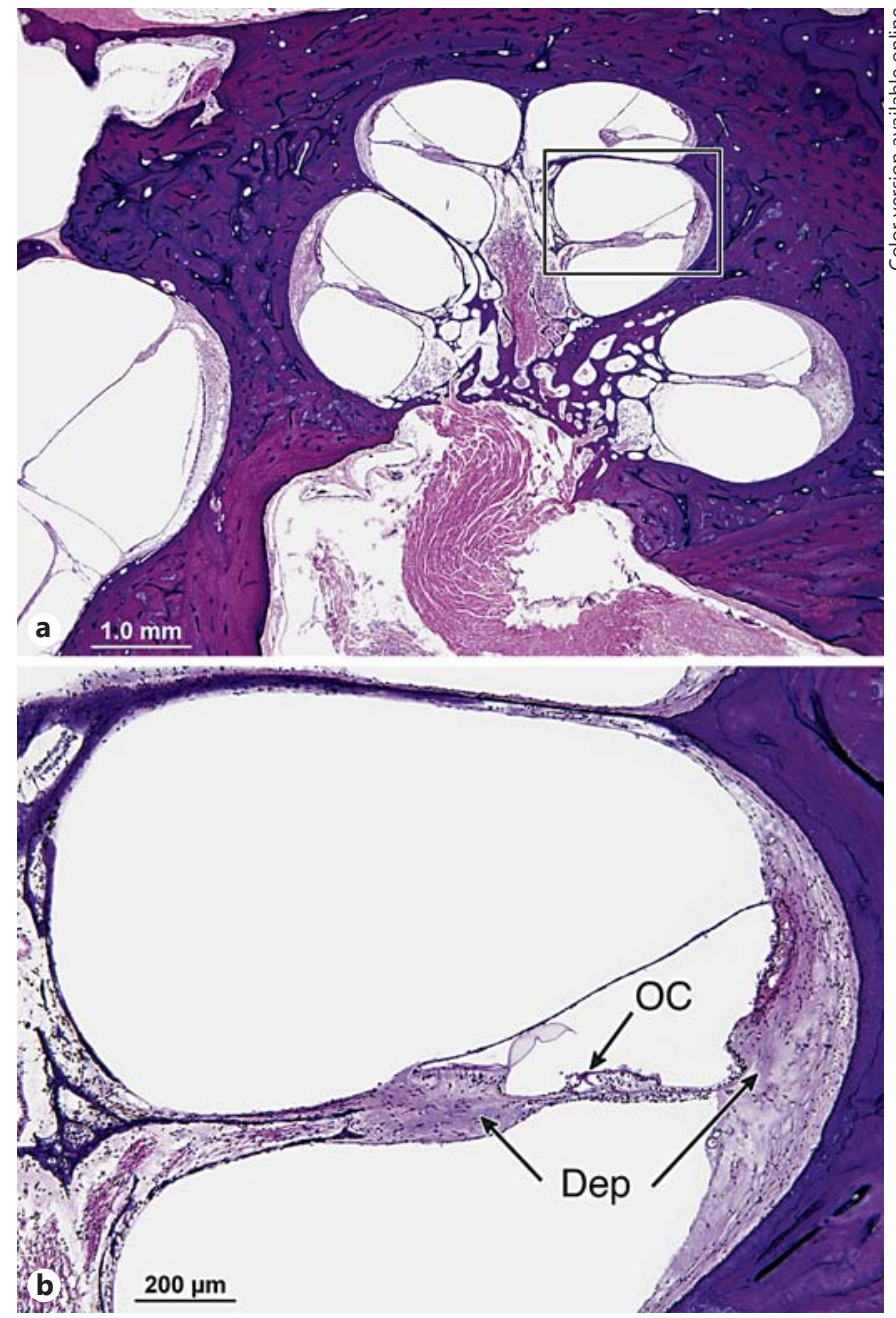

Fig. 4. a Midmodiolar section of the left cochlea. The boxed area is shown at a higher magnification in $\mathbf{b}$. $\mathbf{b}$ Section of the organ of Corti (OC) of the middle turn of the left ear. An amorphous deposit (Dep) is seen in the spiral ligament, at the distal end of the osseous spiral lamina, and at the base of the limbus.

the cochlea, including an amorphous deposit in the spiral ligament and the osseous spiral lamina and limbus, were similar to that described in the left ear. Likewise, the density of spiral ganglion cells was similar to that of the left ear, and the numbers of dendritic processes of the spiral ganglion cells were significantly diminished throughout the cochlea. The vestibular end organs demonstrated moderate atrophy of the neuroepithelium and the presence of amorphous deposits in the mesenchymal tissue between the cribrose area and the neuroepithelium, similar to that described on the left.

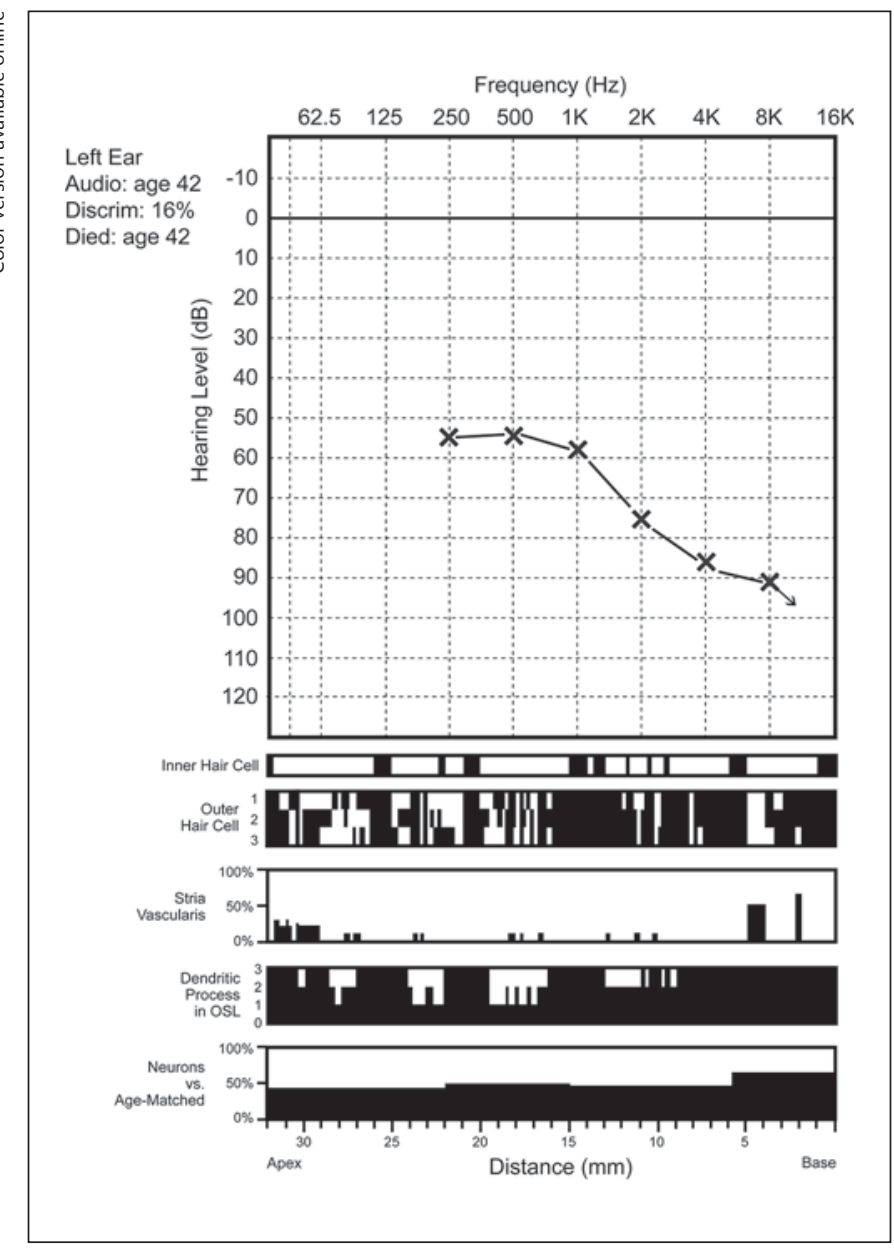

Fig. 5. Cytocochleogram of the left ear. Missing cytological elements are shown in black. There were missing inner and outer hair cells and some atrophy of the stria vascularis. There was a loss of approximately 50 percent of the spiral ganglion cell neurons. However, the dendritic processes between the spiral ganglion cells and the organ of Corti showed the most severe degeneration. Discrim $=$ Discrimination.

\section{Sequence Analysis (fig. 3)}

Given that our analysis of the temporal bone sections by light microscopy revealed a histopathology characteristic of DFNA9 [Khetarpal et al., 1991; Robertson et al., 1998; Merchant et al., 2000], we proceeded with sequencing of $C O C$, with mutations that are causative of DFNA9. Sequence analysis of genomic DNA isolated from the subject's postmortem muscle biopsy revealed a c.T341C missense mutation, resulting in a p.leu114pro (L114P) amino acid change. This mutation has been described previously in a Korean family [Choi et al., 2013] through 


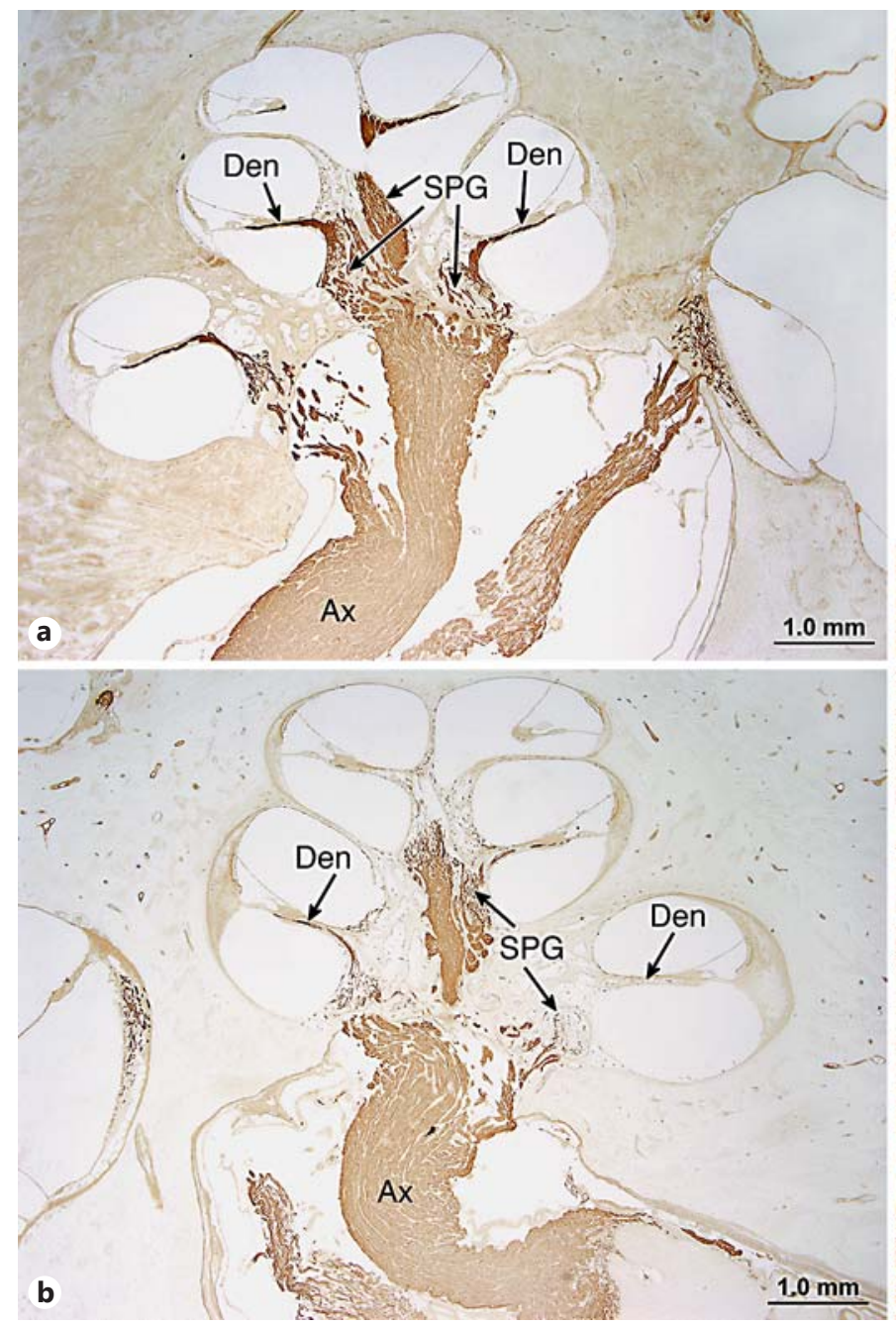

Fig. 6. Myelin protein zero immunostaining of the cochlea. a Midmodiolar section of the control right cochlea from a patient with no otologic disease. b Mid-modiolar section of the left cochlea (subject patient). c Control right ear (basal turn). d Subject patient (left ear, basal turn). In the control ear (a, c), immunostaining for

larger-scale mutation screening of families with sensorineural hearing loss but with no further detailed clinical phenotypic or histological studies.

\section{Discussion}

This 42-year-old male had bilateral progressive sensorineural hearing loss with a marked reduction in speech discrimination scores and our finding of a missense mutation (p.L114P) in COCH (DFNA9). This is the first description of the histopathology of the inner ear in this

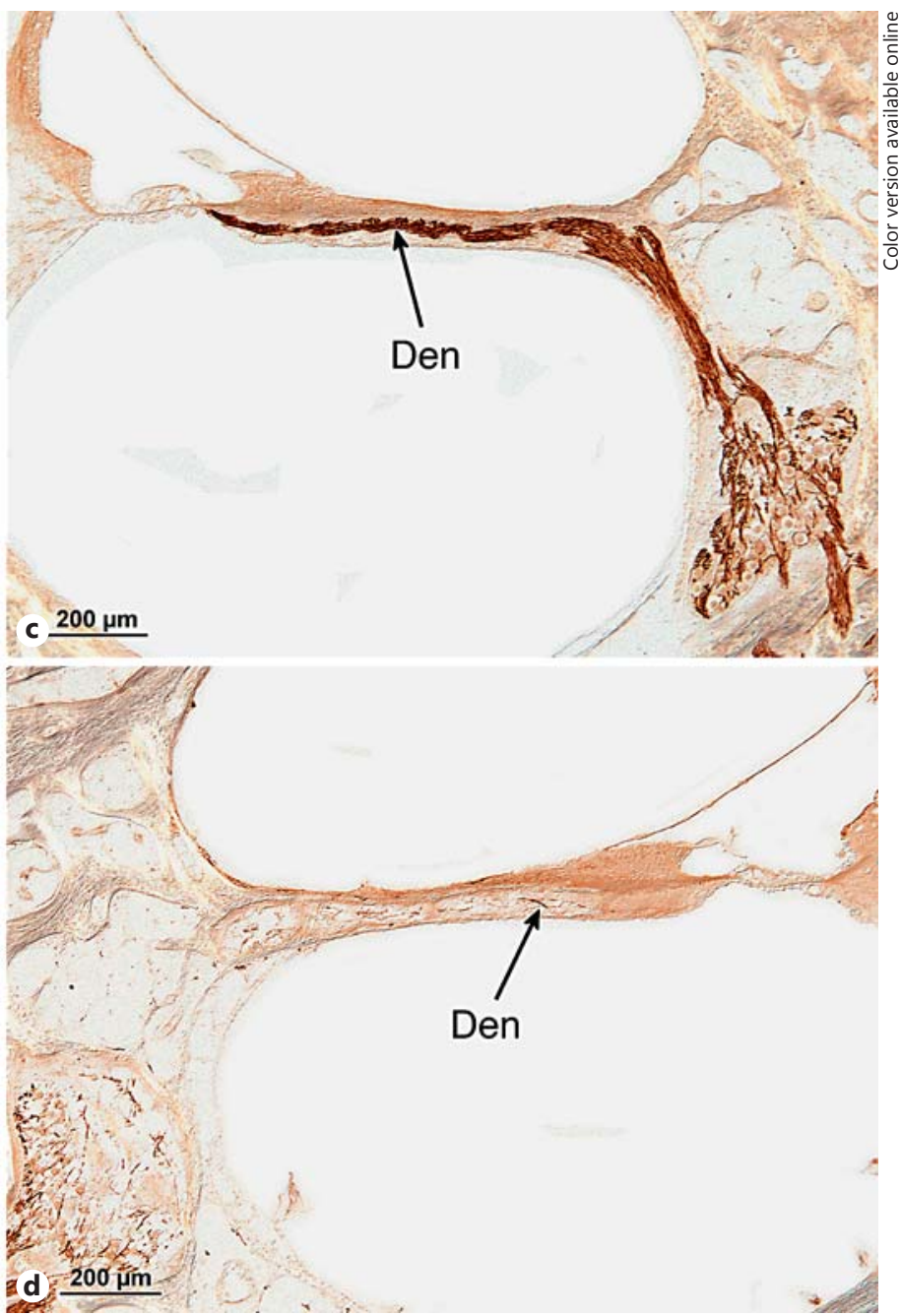

myelin protein zero was positive for axons $(\mathrm{Ax})$, spiral ganglion cells (SPG), and dendritic fibers (Den) within the osseous spiral lamina. In the left cochlea of the subject patient $(\mathbf{b}, \mathbf{d})$, there was a marked reduction of immunostaining of the dendritic fibers. specific mutation. The histopathologic findings were similar to those described in other kinships (table 1), both in the inner ear and in the extracochlear locations as previously reported [McCall et al., 2011; Robertson et al., 2014]. Within the cochlea, the histopathologic findings included a diffuse loss of cellularity of the spiral ligament and accumulation of an extracellular deposit in the spiral ligament, the osseous spiral lamina and the limbus, and the subepithelial mesenchymal tissue of the vestibular neuroepithelium.

In addition to the fact that this is the first description of the otopathology in this specific mutation, there was 


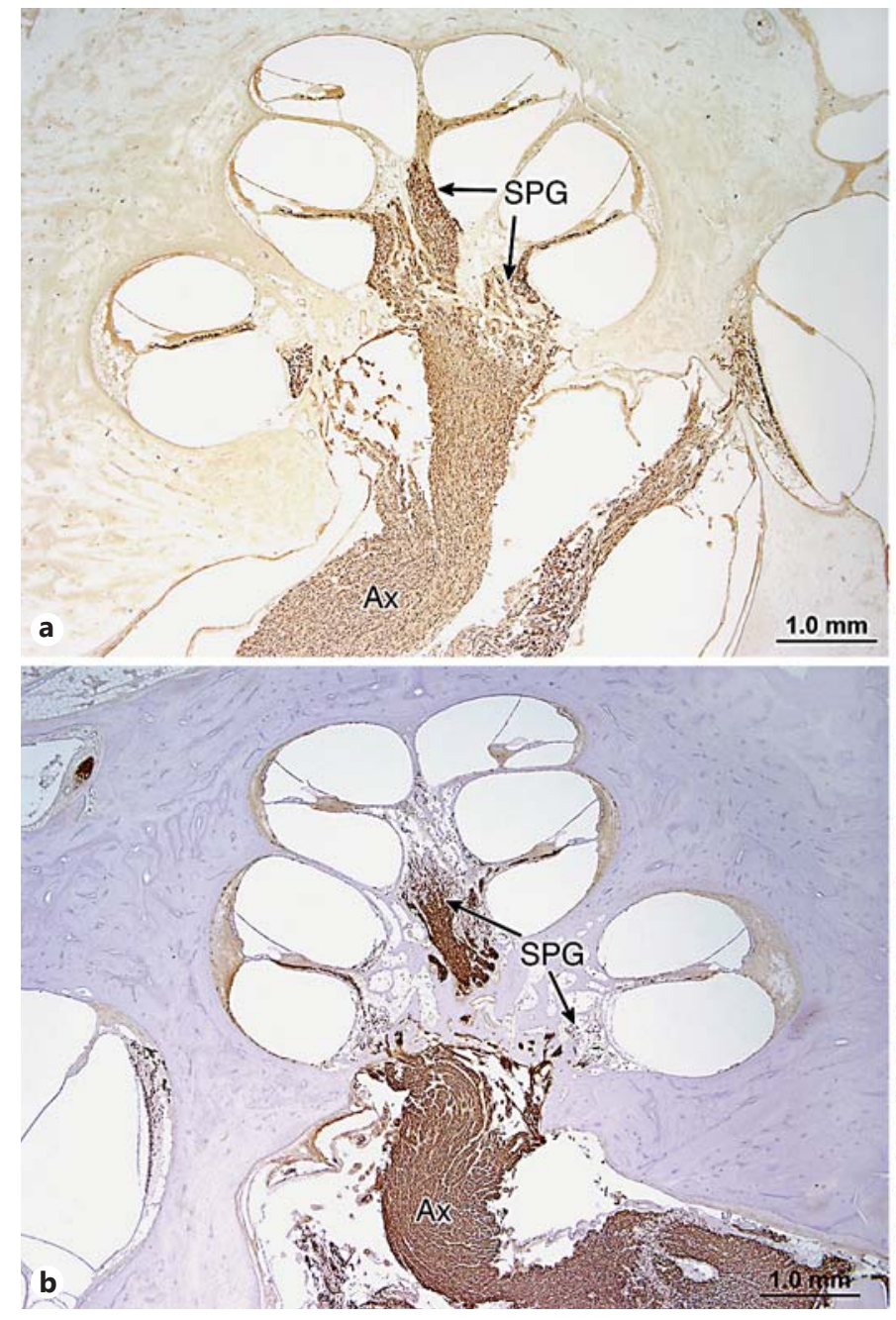

Fig. 7. Anti-neurofilament immunostaining of the cochlea. Midmodiolar section of the right cochlea in the control human. Midmodiolar section of the left cochlea in the subject patient. Basal turn of the cochlea in the control right ear. Basal turn of the cochlea in the left ear of the subject patient. Anti-neurofilament-immu-

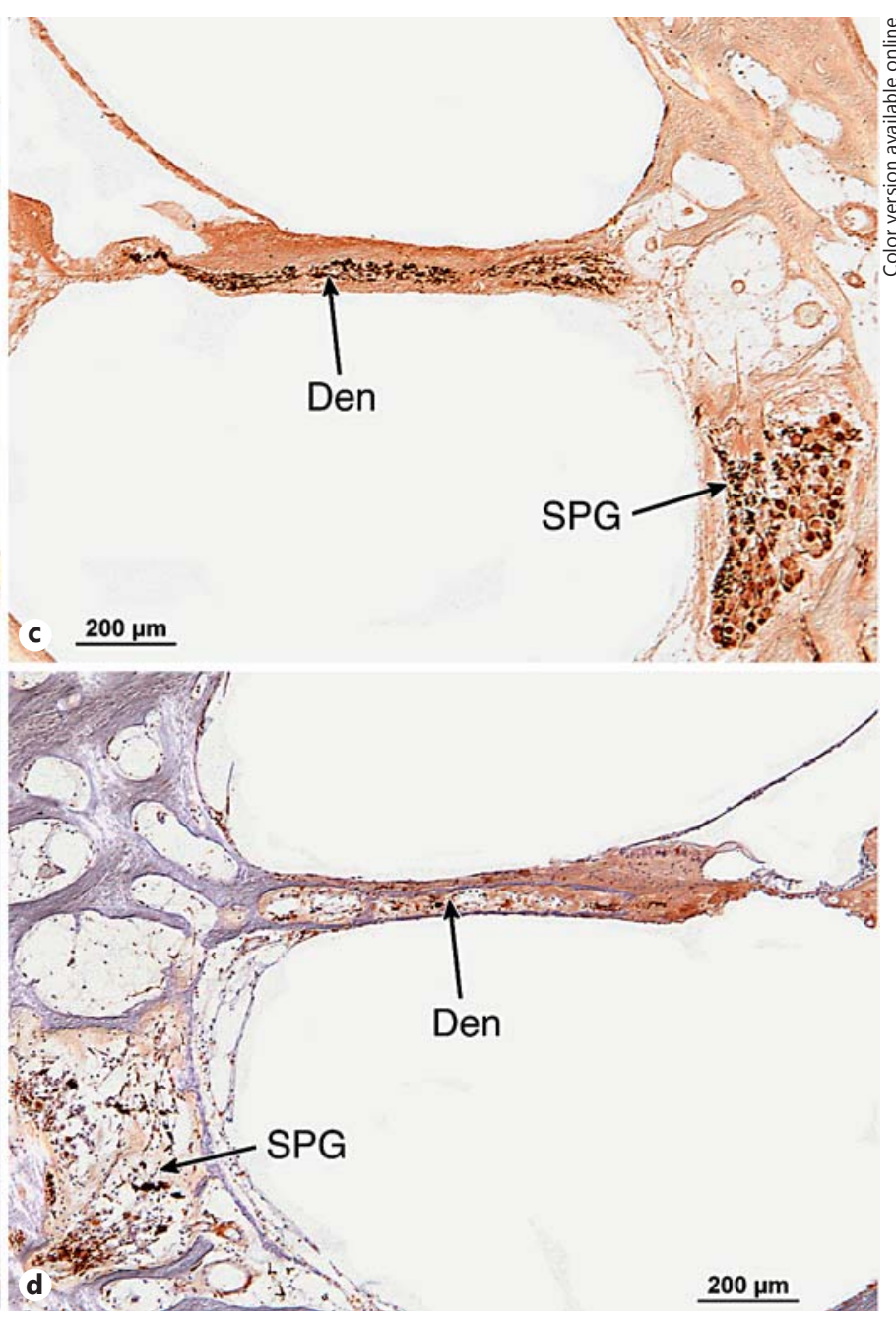

nostained axons (Ax), spiral ganglion cells (SPG), and dendritic fibers (Den). Immunostaining of the dendritic fibers was markedly reduced in the cochlea of the subject patient $(\mathbf{b}, \mathbf{d})$ compared to the normal control $(\mathbf{a}, \mathbf{c})$. considerable residual hearing at the time of death, which offered the opportunity to study further the pathogenesis of hearing loss in DFNA9 given that all 4 previous histopathologic descriptions were of individuals who were profoundly deaf at the time of death.

Although there was degeneration of multiple cytologic elements of the cochlea (fig. 5), the degeneration of the dendritic processes of spiral ganglion cells as seen in the osseous spiral lamina was more advanced than that seen in other cytologic elements, suggesting a primary cochlear neuronal degeneration. Previous published descriptions of the histologic correlate of sensorineural hearing loss in DFNA9 also reported a loss of dendritic fibers of the spiral ganglion cells [Merchant et al., 2000] and suggested that this selective loss of dendritic fibers was perhaps due to dysfunction of the spiral ligament or a direct toxic effect of the deposited material on the dendritic fibers in the osseous spiral lamina. Khetarpal et al. [1991] also suggested a direct deleterious effect on dendritic processes by the deposition of extracellular material in the outer osseous spiral lamina. Robertson et al. [2006] demonstrated that the extracellular deposits are consistent with mutant cochlin and that obstruction of the channels of the osseous spiral lamina by aggregates of this mutant 


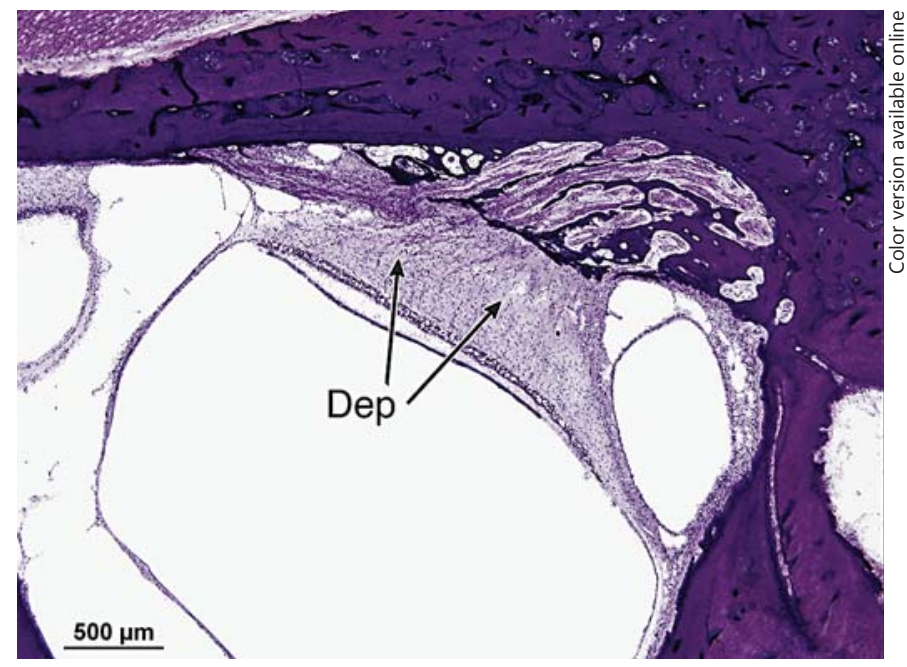

Fig. 8. Utricle of left ear of the subject patient. H\&E. There was a deposit of amorphous material (Dep) in the mesenchymal tissue between the cribrose area and the neuroepithelium of the utricle.

cochlin may be involved in the pathogenesis of neural degeneration.

The case presented herein confirms the previous histological findings of other $\mathrm{COCH}$ mutations and, in addition, given the presence of some preserved hearing at the time of death, it supports the conclusion that the loss of dendritic fibers and of spiral ganglion cells may be a primary event rather than secondary to degeneration of other cytological elements. As shown in figure 5, of all of the cytologic elements quantified, the dendritic fibers showed the most severe degeneration and in particular more degeneration than that of inner hair cells and the spiral ganglion cell bodies. This suggests that the loss of dendrites is not secondary to degeneration of the inner hair cells or the spiral ganglion cell bodies.

Despite the evidence of degeneration of the neuroepithelium of the vestibular system, the presence of an amorphous deposit in the mesenchymal tissue at the base of the neuroepithelium, and the partial atrophy of Scarpa's ganglion cells and degeneration of vestibular dendritic fibers as seen with antineurofilament immunostaining, there was no clinical history of balance or vestibular complaints. This was presumed to be due to a slow degenerative process allowing compensation for a partial loss of vestibular function.

The physiologic role of cochlin in the normal ear is unknown. The location of the expression of $\mathrm{COCH}$ in the human, mouse, and chicken inner ear is identical to that described in patients affected by DFNA9, i.e. the osseous

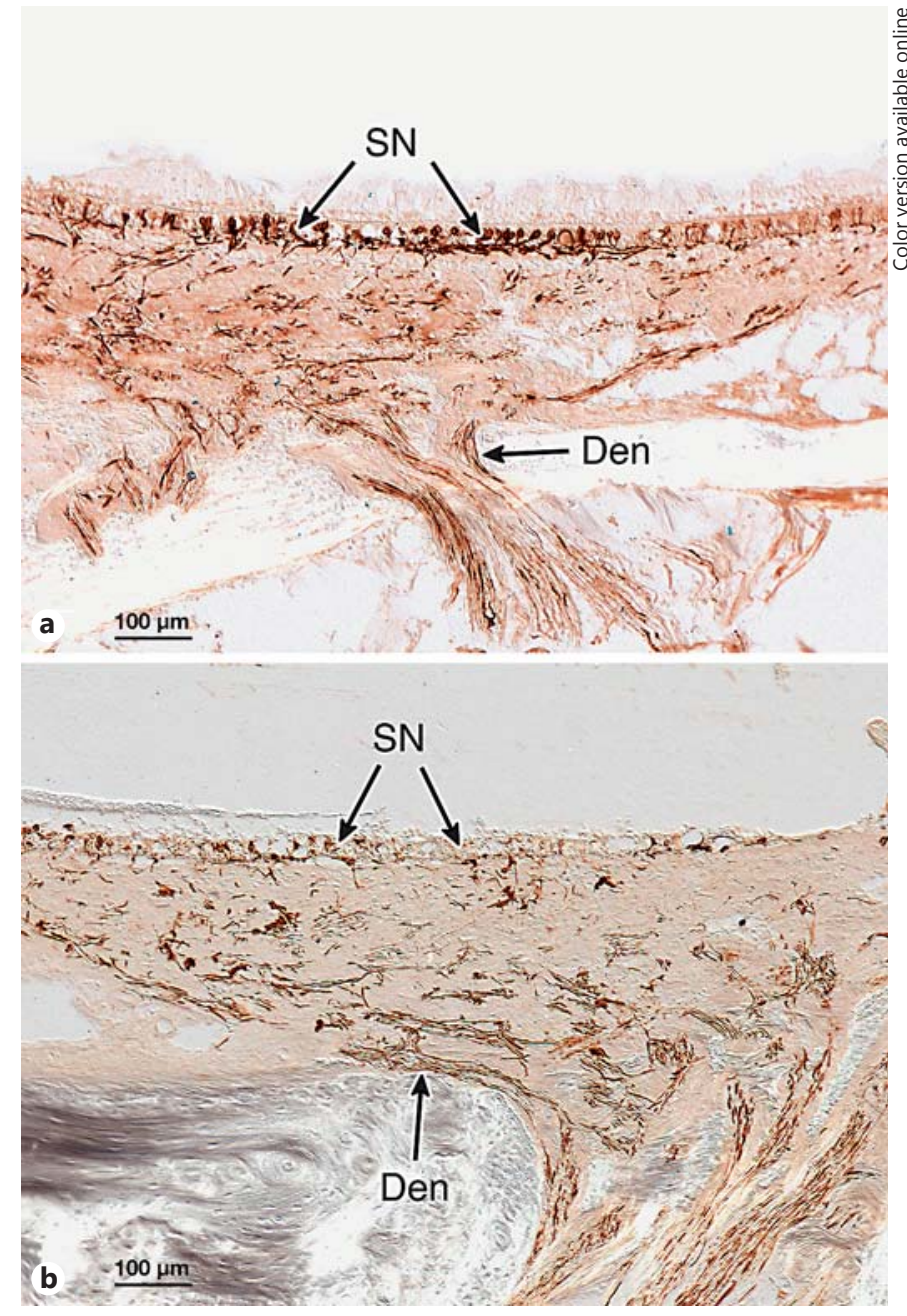

Fig. 9. Antineurofilament immunostaining of the macula sacculi in a control ear (a) and in the subject patient (b). There was a reduction of staining of the dendritic fibers (Den) innervating the saccular neuroepithelium (SN) of the subject patient compared to the control ear.

spiral lamina, the spiral ligament, the limbus, and the stroma of the maculae and cristae [Robertson et al., 1998, 2006]. It has been hypothesized that normal cochlin is involved in antibody-independent host defense mechanisms [Bhattacharya, 2006]. Its expression by follicular dendritic cells of the secondary lymphoid organs and its selective localization in the extracellular network in the spleen and lymph nodes [Py et al., 2013] also suggest a role of cochlin as a modulator of the innate immune response to bacteria.

The role of mutant cochlin in the pathogenesis of disease is equally not fully understood. In DFNA9, it appears 


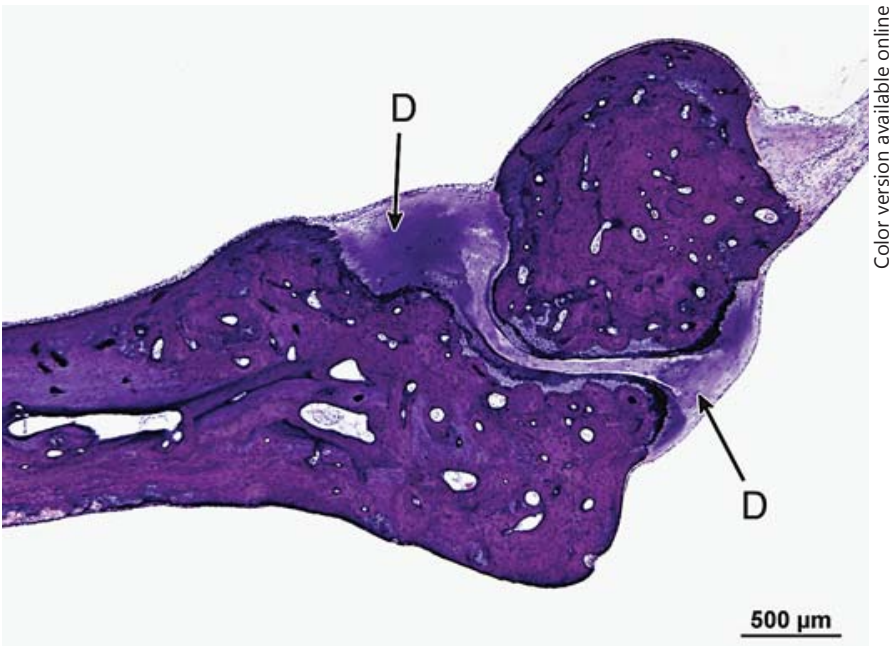

Fig. 10. Incudomalleal joint of subject ear. H\&E. A mixture of basophilic and eosinophilic deposits (D) of amorphous material was seen within the joint space.

that the $\mathrm{COCH}$ mutations result in aggregation of mutated cochlin as part of the extracellular matrix [Robertson et al., 2006], which may play a role in altering extracellular matrix protein interactions [Bhattacharya, 2006] possibly interfering with ionic homeostasis. Similarly, a possible role for cochlin in the causation of glaucoma by aggregated deposits in the trabecular meshwork of the eye has been hypothesized [Bhattacharya, 2006].

A toxic effect on the dendritic processes of spiral ganglion cells was previously suggested by Merchant et al. [2000] and Robertson et al. [2006]. The aggregates of mutated cochlin in the inner ear have been suggested as a possible cause of dendritic degeneration and disruption of ionic cycling [Robertson et al., 2006]. The von Willebrand domains have been suggested to play a role in increased shear-induced platelet aggregation [Bhattacharya, 2006], possibly resulting in vascular disease and secondarily leading to degenerative disease. The pathogenic genetic mechanism underlying aggregates of mutated cochlin is thought to represent a gain of function rather than $\mathrm{COCH}$ haploinsufficiency [Makishima et al., 2005; Robertson et al., 2006; Jones et al., 2011].

\section{Cochlear Implantation in DFNA9}

Given the primary neuronal degeneration, at least at the dendritic level in the organ of Corti in DFNA9, it is somewhat surprising that patients treated with cochlear implants for hearing loss due to DFNA9 do at least as well as other cochlear implant patients with other progressive hearing losses as judged by postoperative word recognition scores [Vermeire et al., 2005]. This implies that, at least in hearing loss caused by DFNA9, electrical stimulation of the auditory nerve does not require the presence of a normal population of dendritic fibers and may actually occur at a more proximal level, i.e. by simulation of the spiral ganglion cell bodies or their central axons.

\section{Acknowledgements}

This study was supported by grants 5R01DC152 (J.B. Nadol Jr.) and 5R01DC03402 (C.C. Morton) from the National Institute on Deafness and Other Communication Disorders (NIH).

\section{Disclosure Statement}

The authors have no conflict of interest.

\section{References}

Bae S-H, Robertson NG, Cho H-J, Morton CC, Jung DJ, Baek J-I, Choi S-Y, Lee J, Lee K-Y, Kim U-K: Identification of pathogenic mechanisms of $\mathrm{COCH}$ mutations, abolished cochlin secretion, and intracellular aggregate formation: genotype-phenotype correlations in DFNA9 deafness and vestibular disorders. Hum Mutat 2014;35:1506-1513.

Bhattacharya SK: Focus on molecules: cochlin. Exp Eye Res 2006;82:355-356.

Choi BY, Park G, Gim J, Kim AR, Kim B-J, Kim H-S, Park JH, Part T, Oh S-H, Han K-H, Park W-Y: Diagnostic application of targeted resequencing for familial nonsyndromic hearing loss. PLoS One 2013;8:1-8.
Jones SM, Robertson NG, Given S, Giersch ABS, Liberman MC, Morton CC: Hearing and vestibular deficits in the $\mathrm{Coch}^{-1-}$ null mouse model: comparison to the $\mathrm{Coch}^{\mathrm{G} 88 \mathrm{E} / \mathrm{G} 88 \mathrm{E}}$ mouse and to DFNA9 hearing and balance disorder. Hear Res 2011;272:42-48.

Khetarpal U: Autosomal dominant sensorineural hearing loss: further temporal bone findings. Arch Otolaryngol Head Neck Surg 1993;119: 106-108.

Khetarpal U: DFNA9 is a progressive audiovestibular dysfunction with a microfibrillar deposit in the inner ear. Laryngoscope 2000;110: 1379-1384.
Khetarpal U, Schuknecht HF, Gacek, RR, Holmes LB: Autosomal dominant sensorineural hearing loss. Arch Otolaryngol Head Neck Surg 1991;117:1032-1042.

Makishima T, Rodriguez CI, Robertson NG, Morton CC, Stewart CL, Griffith AJ: Targeted disruption of mouse Coch provides functional evidence that DFNA9 hearing loss is not a $\mathrm{COCH}$ haploinsufficiency disorder. Hum Genet 2005;118:29-34

McCall AA, Linthicum FH, O'Malley JT, Adams JC, Merchant SN, Bassim MK, Gellibolian R, Fayad JN: Extralabyrinthine manifestations of DFNA9. J Assoc Res Otolaryngol 2011;12: 141-149. 
Merchant SN, Linthicum FH, Nadol JB Jr: Histopathology of the inner ear in DNFA9; in Kitamura K, Steel P (eds): Genetics in Otorhinolaryngology. Basel, Karger, 2000, vol 56, pp 212-217.

Merchant SN, Nadol JB Jr (eds): Schuknecht's Pathology of the Ear, ed 3. Shelton, People's Medical Publishing House, 2010, vol 942, pp 142-147.

O’Malley JT, Burgess BJ, Jones DD, Adams JC, Merchant SN: Techniques of celloidin removal from temporal bone sections. Ann Otol Rhinol Laryngol 2009a;118:435-441.

O’Malley JT, Merchant SN, Burgess BJ, Jones DD, Adams JC: Effect of fixative and embedding medium on morphology and immunostaining of the cochlea. Audiol Neurotol 2009b;14: 78-87.

Py Bf, Gonzalez SF, Long K, Kim M-S, Kim Y-A, Zhu H, Yao J, Degauque N, Villet R, YmeleLeki, P, Gadjeva M, Pier GB, Carroll MC, Yuan J: Cochlin produced by follicular dendritic cells promotes antibacterial innate immunity. Immunity 2013;38:1063-1072.
Robertson NG, Cremers CWRJ, Huygen PLM, Ikezono T, Krastins B, Kremer H, Kuo SF, Liberman MC, Merchant SN, Miller CE, Nadol JB Jr, Sarracino DA, Verhagen WIM, Morton CC: Cochlin immunostaining of inner ear pathologic deposits and proteomic analysis in DFNA9 deafness and vestibular dysfunction. Hum Mol Genet 2006;15:10711085 .

Robertson NG, Hamaker SA, Patriub V, Aster JC, Morton CC: Subcellular localization, secretion, and post-translational processing of normal cochlin, and of mutants causing the sensorineural deafness and vestibular disorder, DFNA9. J Med Genet 2003;40:479-486.

Robertson NG, Lu L, Heller S, Merchant SN, Eavey RD, McKenna M, Nadol JB Jr, Miyamoto RT, Linthicum FH, Neto JFL, Hudspeth AJ, Seidamn CE, Morton CC, Seidman JG: Mutations in a novel cochlear gene cause DFNA9, a human nonsyndromic deafness with vestibular dysfunction. Nat Genet 1998; 20:299-303.
Robertson NG, O’Malley JT, Cheng AO, Giersch ABS, Shen J, Stankovic KM, Morton CC: Cochlin in normal middle ear and abnormal middle ear deposits in DFNA9 and $\mathrm{Coch}^{\mathrm{G} 88 \mathrm{E} / \mathrm{G} 88 \mathrm{E}}$ mice. J Assoc Res Otolaryngol 2014;15:961-974.

Robertson NG, Resendes BL, Lin JS, Lee C, Aster JC, Adams JC, Morton CC: Inner ear localization of mRNA and protein products of $\mathrm{COCH}$, mutated in the sensorineural deafness and vestibular disorder, DFNA9. Hum Mol Genet 2001;10:2493-2500.

Tsukada K, Ichinose A, Miyagawa M, Mori K, Hattori M, Nishio S-Y, Naito Y, Kitajiri S-I, Usami S-I: Detailed hearing and vestibular profiles in patients with $\mathrm{COCH}$ mutations. Ann Otol Rhinol Laryngol 2015;124(suppl 1):100S-110S.

Vermeire K, Brokx, JPL, Wuyts FL, Cochet E Hofkens A, De Bodt M, Van de Heyning PH: Good speech recognition and quality-of-life scores after cochlear implantation in patients with DFNA9. Otol Neurotol 2005;27:44-49. 